\title{
KAJIAN KATA KHUSUS DAN ISLAMISASI MELALUI MANTRA MAKAN DALAM KELAMBU MASYARAKAT BUGIS DENDRENG SEGEDONG MEMPAWAH
}

\author{
Muchammad Djarot \\ Institut Agama Islam Negeri Pontianak \\ Corresponding Email: muhammad_djarot@yahoo.com
}

Received: 10 ${ }^{\text {th }}$ of September 2020, Accepted: $12^{\text {th }}$ of November 2020, Published: $22^{\text {nd }}$ of December 2020

\begin{abstract}
Abstrak
Salah satu suku yang mendiami wilayah Kecamatan Segedong ialah suku Bugis Dendreng. Mantra Makan dalam Kelambu sudah lama dipertahankan menjadi kepercayaannya.. Tradisi tersebut harus dilakukan karena menurut kepercayaan masyarakat tersebut upacara ritual kehidupan sakral dan merupakan bentuk kepercayaan yang masih dipercayai hingga kini. Secara metodologis, penelitian ini tergolong penelitian kualitatif dengan pendekatan pragmatik. Metode yang digunakan dalam penelitian ini adalah metode deskriptif, dengan bentuk penelitian ini merupakan penelitian kualitatif. Teknik pengumpulan data yaitu observasi, wawancara dan dokumentasi serta alat pengumpulan data yaitu lembar observasi, pedoman wawancara, perekam suara dan kamera. Kata khusus dalam sastra lisan mantra Makan dalam Kelambu memainkan peranan penting dalam masyarakat Bugis Dendreng dan merupakan bentuk ungkapan masyarakat Bugis Dendreng agar dalam setiap pelaksanaan pesta perkawinan dapat berjalan dengan lancar. Mantra menjadi pilihan para pendakwah karena masyarakat praIslam sangat percaya dengan hal-hal yang bersifat mistik dan kekuatan gaib.
\end{abstract}

Kata Kunci: kata khusus, islamisasi, mantra

\begin{abstract}
One of the tribes that inhabit the Segedong District is the Bugis Dendreng tribe. The Eating Mantra in Kelambu has long been maintained as his belief. This tradition must be carried out because according to the community's belief, the ritual of life is sacred and is a form of belief that is still believed today. Methodologically, this research is classified as qualitative research with a pragmatic approach. The method used in this research is descriptive method, with the form of this research is qualitative research. Data collection techniques are observation, interviews and documentation and data collection tools are observation sheets, interview guides, voice recorders and cameras. The special word in the oral literature of the mantra Makan dalam Kelambu plays an important role in the Bugis Dendreng community and is a form of expression for the Bugis Dendreng community so that every marriage party can run smoothly. Mantra became the choice of preachers because pre-Islamic society really believed in things that were mystical and supernatural powers.
\end{abstract}

Keywords: special words, islamization, mantra

Copyright $\odot$ Muchammad Djarot

\section{PENDAHULUAN}

Latar belakang yang pluran menjadikan Indonesia sebagai negara yang kaya akan kearifan lokal maupun budaya. Kekhasan itu berupa bahasa, adat istiadat, tradisi atau yang biasa disebut dengan kebiasaan, kepercayaan, kesenian, dan kebudayaan. Bahasa di setiap daerah tentunya berbeda-beda sehingga layak untuk dilestarikan agar tidak punag ditelan zaman. Kebiasaan 
masyarakat yang terlahir dari nenek moyang menjadikan pedoman di setiap suku atau lebih dikenal dengan tradisi. Keyakinan seseorang akan sesuatu yang dianggap paling tinggi dan menyangkut agama seseorang dikenal dengan kepercayaan, sedangkan hasil dari karya atau cipta, pikiran, dan perasaan manusia hingga kini masih dapat dijumpai atau lebih dikenal dengan kebudayaan.

Kebudayaan merupakan cerminan dari kepribadian suatu masyarakat atau golongan. Kebudayaan di suatu daerah menjadi nilai tambah dan nilai positif untuk memperkokoh sistem masyarakat yang ada. Kebudayaan suatu daerah memiliki nilai tinggi bagi bangsa dan negara sehingga dapat menjunjung kebudayaan nasional Indonesia. Suatu kebudayaan pada hakikatnya merupakan tanda pengenal atau identitas diri baik secara individu maupun masyarakat tertentu yang dapat digunakan sebagai alat pengenal dan untuk mengetahui suku bangsa tertentu.

Masyarakat Bugis Dendreng merupakan bagian dari suku Bugis yang tinggal di Desa Gedung Intan, Kecamatan Segedong, Kabupaten Mempawah. Pada dasarnya masyarakat Bugis Dendreng ini bukanlah penduduk asli di desa tersebut melainkan pendatang yang telah lama menetap, namun masyarakat tersebut tetap menjaga kebudayaan dan tradisi berupa sastra lisan yang berbentuk mantra yaitu Makan dalam Kelambu. Bagi masyarakat Bugis Dendreng, mantra Makan dalam Kelambu sudah menjadi tradisi yang harus dilakukan karena menurut kepercayaan masyarakat tersebut upacara ritual kehidupan sangat sakral dan merupakan salah satu bentuk kepercayaan yang masih dipercayai sampai sekarang.

Mantra merupakan bentuk sastra lisan dan merupakan bagian dari kebudayaan bangsa Indonesia yang diwariskan secara hingga kini di tengah masyarakat Indonesia khususnya masyarakat Bugis Dendreng Kecamatan Segedong Mempawah. Sebagai bagian dari kebudayaan Indonesia yang tumbuh dan berkembang, sastra lisan mempunyai fungsi dan kedudukan di tengah-tengah kehidupan masyarakat penuturnya, seperti sebagai alat penghibur, alat komunikasi dalam pergaulan muda-mudi, dan sebagai sarana kekuatan magis.

Menurut Hutomo (1991:1), sastra lisan adalah kesusasteraan yang mencakup ekspresi kesusasteraan warga suatu kebudayaan yang disebarkan dan diturun-temurunkan secara lisan (dari mulut ke mulut). Sastra tersebut terus menerus dilestarikan dari satu generasi ke generasi berikutnya. Oleh karena itu, sastra lisan merupakan bentuk hasil karya cipta suatu masyarakat yang diwariskan dari turun-temurun secara lisan. Sastra lisan bermanfaat dan berperan sebagai kekayaan budaya khususnya kekayaan sastra Indonesia. Salah satu bentuk sastra lisan yaitu mantra. 
Mantra masih mewarnai kehidupan manusia dan masih sangat diperlukan baik untuk kepentingan yang bersifat positif maupun yang negatif. Walau dunia semakin modern, mantra masih berperan penting di tengah-tengah masyarakat sekarang ini.

Mantra juga dapat berarti susunan kata-kata atau kalimat yang mengandung kekuatan gaib. Mantra hanya dapat diucapkan dalam waktu tertentu dan tidak dapat diucapakan oleh sembarang orang. Mantra hanya dapat diucapkan oleh seorang dukun yang sudah berpengalaman dan dipercayai oleh masyarakat setempat untuk berhubungan dengan mahluk gaib.

Mantra digunakan untuk sesuatu yang positif, baik untuk keperluan keyakinan maupun adat istiadat suatu masyarakat. Mantra berisikan pujian terhadap sesuatu yang baik, seperti Tuhan, dewa, roh-roh binatang atau benda yang dikeramatkan, yang di ucapkan dukun apabila mengadakan upacara adat. Mantra dipercayai oleh masyarakat pendukungnya yang mempercayai dapat memberikan kekuatan gaib untuk menolak segala penyakit, baik diakibatkan perbuatan jahil manusia maupun roh jahat.

Menurut Gimlette (dalam Hermansyah, 2010:41) mantra berasal dari bahasa sansekerta, yaitu "manir", atau "minar" yang dalam masyarakat Melayu merujuk kepada bacaan dan wirid yang bersifat gaib.Mantra juga dapat berarti susunan kata-kata atau kalimat yang mengandung kekuatan gaib. Mantra hanya dapat diucapkan dalam waktu tertentu dan tidak dapat diucapakan oleh sembarang orang. Mantra hanya dapat diucapkan oleh seorang dukun yang sudah berpengalaman dan dipercayai oleh masyarakat setempat untuk berhubungan dengan mahluk gaib.

Seiring perkembangan zaman tradisi ini jarang sekali dilakukan, dikarenakan adanya pengaruh budaya luar, pengaruh agama yang dianut, serta keadaan perekonomian masyarakat, mereka beranggapan bahwa hal upacara ritual kehidupan adalah syirik, maka ada sebagian masyarakat yang menghilangkan upacara ritual kehidupan ini.

Berdasarkan latar belakang tersebut, penulis tertarik untuk meneliti satu di antara kebudayaan daerah yang berupa mantra pada masyarakat Adat Bugis Dendreng di Desa Gedung Intan kecamatan Segedong kabupaten Mempawah, adapun objek yang menjadi penelitian adalah mantra, yakni mantra yang terdapat dalam upacara ritual kehidupan yang terdiri dari makan dalam kelambu, kasi makan bumi, ritual turun tanah, dan ritual tujuh bulan. penulisan ini menekankan bahasa sebagai medium untuk untuk mengeksprsikan karya sastra yang berupa mantra. Bahasa mempunyai unsur semantiknya yang berhubungan erat, misalnya keindahan bunyi, rima, dan irama. Hal ini dikemukakan oleh Waluyo (1991:7) bahwa, "Bunyi- 
bunyi yang berulang ini menciptakan konsentrasi dan kekuatan bahasa atau sering disebut daya gaib kata seperti dalam mantra".

\section{METODE}

Metode deskriptif merupakan metode yang peneliti gunakan. Metode ini digunakan untuk memaparkan data yang diperoleh dalam penelitian ini. Nawawi (1992: 63) menyatakan bahwa metode penelitian deskriptif dapat diartikan sebagai prosedur pemecahan masalah yang diselidiki dengan menggambarkan atau melukiskan keadaan subjek/objek penelitian (seseorang, lembaga, masyarakat, dan lain-lain) pada saat sekarang berdasarkan fakta-fakta yang tampak dan sebagaimana mestinya. Metode ini digunakan untuk menggambarkan apa adanya hasil dari pengumpulan data yang telah dilakukan oleh penulis. Metode deskriptif dipilih oleh penulis karena metode ini dapat memberikan gambaran yang secermat mungkin mengenai individu, keadaan bahasa, gejala atau kelompok tertentu. Kajian deskriptif menurut Chaer (2007: 9) biasanya dilakukan terhadap struktur internal bahasa, yakni struktur bunyi (fonologi), struktur kata (morfologi), struktur kalimat (sintaksis), struktur wacana dan struktur semantik. Kajian deskriptif ini dilakukan dengan mula-mula mengumpulkan data, mengklasifikasi data, lalu merumuskan kaidah-kaidah terhadap keteraturan yang terdapat pada data itu. Pada dasarnya rumusan kaidah terhadap keteraturan yang terdapat pada data itu tidak lain daripada "teori" terhadap data itu. Selama data yang ditemukan tidak menumpang dari status keteraturan maka teori itu tetap dapat diterima; tetapi apabila terdapat data yang menyimpang, maka teori tersebut harus ditinjau kembali.

\section{HASIL DAN PEMBAHASAN}

\section{Mantra Sebagai Bagian dari Sastra Lisan}

Mantra merupakan puisi tertua di Indonesia yang terdapat di dalam kesusastraan daerah. Kesusastraan tersebut mercerminkan hakikat puisi Melayu lama yakni kombinasi data yang dimaksudkan penciptaannya untuk menimbulkan kekuatan gaib atau daya magis. Zainul dkk (2002:21) mengatakan bahwa puisi rakyat adalah jenis sastra daerah yang berbentuk puisi. Dalam sastra lisan Aji, puisi rakyat meliputi jambi (mantra), tembang (pantun yang dilagukan), kuchan atau undak-undak (pantun), puisi dalam pergaulan anak-anak, adi-adi, ngenjok adok (puisi dalam pemberian gelar menuntut adat), ngejok drama 'pemberian nama' dan iring-iring”.

Sedangkan sastra lisan adalah satu di antara bagian dari budaya yang dimiliki oleh masyarakat secara turun temurun yang dituturkan dari satu orang ke orang lain atau dari generasi ke generasi yang merupakan produk budaya, hasil strukturisasi pikiran manusia masa lampau yang di dalamnya tersimpan sebagai macam budaya yang masih relevan dengan kehidupan masa kini. 
Sastra lisan memiliki fungsi tersendiri dalam masyarakat. Hal tersebut berkaitan dengan aspek sosiologis karya sastra karena berkaitan dengan masyarakat pemiliknya. Adapun fungsi sastra tersebut yaitu: (a) sebagai sistem proyeksi; (b) sebagai alat pengesahan kebudayaan; (c) sebagai alat pemakarsa berlakunya norma-norma sosial dan sebagai alat pengendali sosial; (d) sebagai pendidik anak; (e) jari tangan kita itu menurut orang Jawa satu sama lain mempunyai ikatan persaudaraan dan jari tangan kita itu digunakan untuk pendidikan anak-anak kita; (f) untuk memberikan seseorang suatu jalan yang diberikan oleh masyarakat agar dia dapat mencela orang lain; (g) sebagai alat untuk memprotes ketidakadilan dalam masyarakat; (h) untuk melarikan diri dari himpitan hidup sehari-hari (Hutomo, 1991;69). Berdasarkan pendapat tersebut maka mantra merupakan bagian dari sastra lisan.

Mantra adalah kata-kata hikmat yang mengandung kekuatan gaib yang diucapkan dukun dan tidak semua orang boleh mengucapkannya karena menurut kepercayaan dapat mendatangkan bahaya. Mantra hanya diucapkan atau dibacakan oleh dukun ketika diadakan upacara adat dan dilengkapi dengan beberapa sesajen.

Dukun biasanya mempergunakan bahasa sehari-hari yang dianggap memiliki makna dalam kehidupan masyarakat pendukungnya. Dukun tersebut akan menggunakan mantra yang terdapat unsur-unsur pemujaan kepada Tuhan agar makhluk halus tidak menggangu kehidupan manusia. Oleh krena itu, mantra sesungguhnya merupakan media manusia untuk berhubungan dengan kekuatan yang bersifat gaib sehingga d perlukan proses pembacaan secara konsentrasi penuh.

Kekuatan gaib dalam mantra timbul karena adanya keyakinan dari pembaca mantra akan mantra yang dibacakannya. Selain itu, ada hal-hal yang dilakukan sebagai pembuktian untuk mengetahui apakah mantra yang dibacanya itu memiliki efek atau tidak untuk dirinya sendiri dan orang lain. Kekuatan gaib dalam mantra timbul karena adanya keyakinan pembaca mantra yang dibacanya tersebut.

\section{Kajian Kata Khusus Mantra Makan Dalam Kelambu}

Kata khusus adalah kata-kata yang jarang atau kurang umum digunakan dalam kehidupan sehari-hari masyarakat masyarakat Bugis Dendreng Desa Gedung Intan Kecamatan Segedong Kabupaten Mempawah. Mantra makan dalam kelambu adalah mantra yang digunakan untuk melancarkan proses pesta perkawinan. Kata-kata khusus yang ditemukan dalam mantra Makan dalam Kelambu sebagai berikut. 
O paleleng ajok kaco-kaco andikmu

kalo kaco-kaco ajok rampai-rampai

ajok rasoi-rasoi, kalo iko rampai andikmu

Lailahaillallah

Ali mengkerawak ati puteh nelano, perekat Lailahaillallah

Saksi iwana puako, Muhammad, Jibril, kumpiakong

Lapa tempo, asenah cemellebak sirpaku terbayang-bayang

Ali besi relano muareng rasenah ponalidamu capak lidamu relano dekneriko engkana riak

Kata khusus pada mantra makan dalam kelambu dalam masyarakat Bugis Dendreng Desa Gedung Intan Kecamatan Segedong Kabupaten Mempawah adalah pada baris pertama yaitu $O$ paleleng ajok kaco-kaco andikmu. Kata O paleleng ajok kaco-kaco andikmu memiliki makna Kalau lewat jangan ganggu-ganggu adikmu. Penutur menyebut ajok kaco-kaco dengan maksud bahwa pada saat akan rencana pelaksanakan sampai akhir pesta pernikahan diharapkan makhluk halus jangan mengganggu acara tersebut agar pesta perkawinan berjalan dengan lancar.

Kata ajok rampai-rampai memiliki makna bahwa jika ganggu jangan dekat-dekat. Pesta perkawinan merupakan acara sakral yang sudah direncanakan jauh hari dengan persiapan yang maksimal sehingga harapan semua orang pelaksanaan pesta perkawinan tersebut dapat berjalan dengan lancar. Dalam kepercayaan masyarakat Bugis Dendreng Desa Gedung Intan Kecamatan Segedong Kabupaten Mempawah, dulunya kadang-kadang pelaksanaan pesta perkawinan tersebut tidak maksimal dan ada saja kekurangan atau masalah. Masalah tersebut menurut kepercayaan masyarakat Bugis Dendreng Desa Gedung Intan Kecamatan Segedong Kabupaten Mempawah disebabkan oleh kekuatan lain di luar kemampuan manusia, bisa berupa kekuatan magis. Menurut ajaran agama, pesta perkawinan tersebut tidak maksimal dan ada saja kekurangan atau masalah karena ada kekuatan lain di luar nalar manusia yaitu Allah SWT, sebagai manusia hanya bisa berusaha dan berdoa sedangkan hasil dari semua usaha kita serahkan kepada Allah SWT.

Kata ajok rasoi-rasoi, kalo iko rampai andikmu bermakna jika kamu bercanda, jika kamu dekat adikmu. Kalimat ajok rasoi-rasoi, kalo iko rampai andikmu menunjukkan kepercayaan masyarakat Bugis Dendreng Desa Gedung Intan Kecamatan Segedong Kabupaten Mempawah bahwa jangan sampai pada pelaksanaan pesta perkawinan terjadi hal-hal yang tidak diinginkan.

Kata Lailahaillallah bermakna tiada Tuhan selain Allah SWT. Kalimat tersebut menyatakan bahwa jika ada masalah berkaitan pelaksanaan pesta perkawinan yang disebabkan 
oleh makhluk halus, maka masyarakat Bugis Dendreng Desa Gedung Intan Kecamatan Segedong Kabupaten Mempawah juga memohon perlindungan dari Allah SWT.

Kata Ali mengkerawak ati puteh nelano perekat lailahaillallah bermakna Ali memegang seluruh yang ada di sekitar, perekat tiada Tuhan selain Allah, Ali merupakan tokoh terpandang yang diyakini memiliki kekuatan magis dan selalu diminta oleh masyarakat Bugis untuk melindungi pelaksanaan pesta perkawinan di Desa Gedung Intan Kecamatan Segedong Kabupaten Mempawah. Masyarakat Bugis Dendreng Desa Gedung Intan Kecamatan Segedong Kabupaten Mempawah juga memercayai bahwa suksesnya pesta perkawinan tidak lepas dari kuasa Allah SWT.

Kata Saksi iwana puako, Muhammad, Jibril, kumpiakong bermakna Aku bersaksi kepada Allah, selamat Muhammad, Jibril, pasti jadi. Kata puake menurut masyarakat Bugis Dendreng berarti kekuatan besar di luar kemampuan manusia yaitu Allah SWT. Kata Muhammad merupakan orang pertama yang mensyiarkan agama Islam, kata Jibril merupakan malaikat yang mengantarkan wahyu.

Kata Lapa tempo, asenah cemellebak sirpaku terbayang-bayang yang bermakna Pasti jadi, istriku yang memandang rupaku akan teringat selalu. Ketika mantra ini dibacakan maka sang calon pengantin perempuan/istri akan selalu terbayang-bayang atau selalu teringat dengan sang suami. Kalimat tersebut juga mengajarkan agar sang istri menyayangi suaminya sepenuh hati dan menerima segala kekurangan yang dimiliki oleh suami.

Kata Ali besi relano muareng rasenah ponalidamu capak lidamu relano dekneriko engkana riak bermakna Hati besi istriku asal namaku disebut oleh pangkal lidahmu tidak ada yang berani denganku. Kalimat tersebut menyatakan bahwa ketika nama suami disebut oleh istri maka seorang istri tidak akan pernah berani melawan suaminya dan selalu menurut apa yang diinginkan suaminya. Kalimat tersebut juga mengajarkan bahwa sebagai seorang istri selayaknya patuh kepada suami sebagai imam atau pemimpin dalam rumah tangga.

\section{Islamisasi Melalui Sastra Lisan Mantra Makan Dalam Kelambu}

Sebelum beragama Islam, masyarakat Bugis Dendreng itu animis yang memercayai semua benda yang tidak bernyawa dan alam mempunyai roh hidup yang dikenal sebagai semangat, badi, atau penunggu. Konsep ini merupakan peninggalan dari zaman animisme dan warisan dari nenek moyang sebagai historis yang ketika Islam datang disesuaikan dengan Islam. Artinya, amalan magis tersebut berasaskan pada kepercayaaan warisan ini diturunkan secara lisan sejak lama. Ketika kedatangan pengaruh Hindu-Budha, unsur-unsur kepercayaan dari agama itu memengaruhi amalan magis tradisi. 
Apabila orang-orang Bugis menerima Islam, amalan magis ini pula disesuaikan dengan kehendak Islam. Misalnya dengan memasukkan unsur-unsur Islam dalam amalan magis itu yang dengan sendirinya amalan itu dianggap membawa nilai-nilai Islam. Sebenarnya dalam kasus-kasus mantra Bugis pengaruh animisme lebih dominan diwariskan langsung kepada masyarakat Bugis daripada pengaruh Hindu-Budha. Artinya, dalam mantra Bugis yang pernah diteliti sangat sedikit mantra-mantra Bugis yang mempunyai hubungan langsung dengan ajaran Hindu-Budha. Mantra-mantra Bugis warisan animisme ini kemudian banyak dipengaruhi Islam dengan memasukkan unsur "Lailahaillallah, Muhammad, Jibril"

Mantra menjadi pilihan para pendakwah karena masyarakat praIslam sangat percaya dengan hal-hal yang bersifat mistik dan kekuatan gaib. Mantra tertentu dianggap dapat memberi perlindungan, pengasihan, dan pengobatan serta kemenangan dalam sebuah pertandingan dan/atau peperangan. Daya tarik mantra yang sangat besar dalam kehidupan mistik dan metafisika menjadi sebuah strategi damai dalam mengislamkan masyarakat tanpa harus menumpahkan darah dan pemaksaan sehingga Islam dapat diterima dan dianut oleh masyarakat. Tidak mengherankan mantra dimiliki oleh individu masyarakat di Nusantara sebagai bekal diri dalam kehidupan sehari-hari untuk pengobatan, perlindungan, dan pengasihan. Bahkan, mantra pengobatan yang biasanya dimiliki oleh orang-orang khusus, seperti dukun atau bomoh pun ikut diselipkan kalimat syahadat sebagai bagian dari proses Islamisasi.

\section{SIMPULAN}

Kata khusus dalam sastra lisan mantra Makan dalam Kelambu memainkan peranan penting dalam masyarakat Bugis Dendreng dan merupakan bentuk ungkapan masyarakat Bugis Dendreng agar dalam setiap pelaksanaan pesta perkawinan dapat berjalan dengan lancar. Kata khusus yang digunakan masyarakat Bugis Dendreng cenderung menggunakan bahasa daerah setempat dan menggunakan kata-kata yang berasal dari bahasa Arab dikarenakan adanya pengaruh unsur animisme dan unsur agama Islam yang telah masuk ke masyarakat setempat. Unsur kata-kata yang bernuansa keislaman turut berpengaruh dikarenakan masyarakat Bugis Dendreng telah memeluk Islam sebagai bentuk keyakinan terhadap Tuhan tetapi unsur animisme juga masih erat dipegang sebagai bentuk kecintaan terhadap budaya dan kearifan lokal masyarakat setempat.

Mantra menjadi pilihan para pendakwah karena masyarakat praIslam sangat percaya dengan hal-hal yang bersifat mistik dan kekuatan gaib. Mantra tertentu dianggap dapat memberi perlindungan, pengasihan, dan pengobatan serta kemenangan dalam sebuah pertandingan dan/atau peperangan. Daya tarik mantra yang sangat besar dalam kehidupan 
mistik dan metafisika menjadi sebuah strategi damai dalam mengislamkan masyarakat tanpa harus menumpahkan darah dan pemaksaan sehingga Islam dapat diterima dan dianut oleh masyarakat. Tidak mengherankan mantra dimiliki oleh individu masyarakat di Nusantara sebagai bekal diri dalam kehidupan sehari-hari untuk pengobatan, perlindungan, dan pengasihan. Bahkan, mantra pengobatan yang biasanya dimiliki oleh orang-orang khusus, seperti dukun atau bomoh pun ikut diselipkan kalimat syahadat sebagai bagian dari proses Islamisasi.

\section{REFERENSI}

Chaer, Abdul. (2007). Kajian Bahasa Struktur Internal, Pemakaian dan Pemelajaran. Jakarta: Rineka Cipta.

Hermansyah. (2010). Ilmu Gaib di Kalimantan Barat. Jakarta: Kepustakaan Populer Gramedia. Hutomo, Suripan Sadi. (1991). Mutiara yang Terlupakan Pengantar Sastra Lisan. Surabaya: Hiski.

Moleong, Lexy J. (2013). Metode penelitian Kualitatif. Bandung: Remaja Rosdakarya.

Nani, Valentina. (2010). "Mantra dalam Upacara Balala' Satra Lisan Dayak Kanayatn Kecamatan Sampok Kabupaten Landak”. Pontianak: FKIP Untan.

Nawawi, Hadari. (1992). Instrumen Penelitian Bidang Sosial. Yogyakarta. Gadjah Mada University Press.

Satori, Djam'an dan Aan Komariah. (2009). Metodologi Penelitian Kualitatif. Bandung: Alfabeta.

Suhardi dan Riauwati, “Analisis Nilai-Nilai Budaya (Melayu) dalam Sastra Lisan Masyarakat Kota Tanjungpinang", dalam Jurnal Lingua, vol. 13. No. 1 (2017).

Suantoko. "Fungsi Sastra Lisan "Tanduk" Masyarakat Genaharjo Kabupaten Tuban Bagi Masyarakat Pendukungnya" dalam Jurnal Bahasa dan Sastra, Vol 16, No 2 (2016), hlm. 247.

Sudaryanto. (1993). Metode Linguistik: Ke Arah Memahami Metode Linguistik. Yogyakarta: Gadjah Mada University Press.

Waluyo, Herman J. (1991). Teori dan Apresiasi Puisi dan Prosa. Jakarta: Erlangga.

Zekriady. "Analisis Bentuk dan Makna Sastra Lisan Sumbawa Sakeco Suku Samawa di Kabupaten Sumbawa dengan Pendekatan Foklor”, dalam Jurnal Artikulasi, Vol.6 No.2 (Agustus 2008).

Zainul, Arifin, dkk. (2002). Struktur Sastra Lisan Aji. Jakarta: Pusat Bahasa. 